\title{
An Analytical Method of Deflection Behavior Concerning Three-dimensional Steel Frame Exposed to Fire which takes Account of the Thermal Expansion of a Floor Slab
}

\author{
Yuguang $\mathrm{Li}^{1}$, Huiqun $\mathrm{Lin}^{2}$, Takeo Hirashima ${ }^{3}$, Hideki Uesigi ${ }^{4}$ and Takao Wakamatsu \\ ${ }^{1}$ Department of Architecture, Graduate School of Science and Technology, Tokyo University of Science \\ ${ }^{2}$ Post Doctor of Chiba University \\ ${ }^{3}$ Faculty of Engineering, Chiba University \\ ${ }^{4}$ Graduate School of Science and Technology, Chiba University \\ ${ }^{5}$ Research Institutes for Science and Technology, Tokyo University of Science
}

\begin{abstract}
It is natural to treat a building structure as a $3 \mathrm{D}$ body when concerning its behavior in a fire, because fire is a phenomenon involving 3D thermal expansion. The influence that the floor slab in a fire compartment exposed to fire has on the behavior of the building structure during a fire may be extremely large, therefore, it is necessary to explore how the floor slab affects the structure when exposed to fire. In this study, the end restraint force and the displacements of the adjacent substructures are formulated by dividing structures into unitary substructures, as an approach to the problem of the increase in the number of nodes which occurs in the 3D analysis taking account of the slab. Since no basic data is available for concrete under 2D stress exposed to elevated temperatures, the thermal expansion of a floor slab is considered by conceiving the slab as a grid of intersecting beams. A method of 3D coordinate transformation, which takes the effect caused by the principal axis of component section moving from time to time into account, is proposed. Under these assumptions, an analytical method of deflection behavior concerning 3D steel frame exposed to fire that takes account of the thermal expansion of a floor slab is constructed. The theoretical results agree well with those recorded in experiments in which a full-scale frame was exposed to vehicle fire.
\end{abstract}

Keywords: fire, thermal stress analysis, steel frame, 3D analysis, floor slab

\section{INTRODUCTION}

The collapse of the WTC Building in New York has remotely demonstrated that the method of evaluating the fire resistance performance of the entire building through experimenting on the fire resistance performance of the individual components such as columns, beams, and floors, is reaching the limit of its capability. A new type of design method taking the interaction between these members into consideration needs to be established.

To assure the fire safety of the construction in the case of a fire incident, the main focus would obviously be to prevent the fire from spreading within the building. Measures are taken to divide the interior of the building into separate fire 
compartments to seal off the fire within the compartment where it has originated. A fire resistance performance to hold out under the standard heating condition for 1-3 hours is requested, in general, against the separating components(floors and walls) and the frame components(columns and beams)[1]. The fire resistance performances of these components are verified by placing each individual component under a stress equivalent to the "Allowable Stress for Long Term Load" and performing the Standard Heating Test. However, the influence of the interactions between the components cannot be considered in this verification method. The stress-deformation behavior of the structural frame to be exposed to fire is governed by several elements: the degradation of the strength of the components ruled by the mechanical characteristics of the material used; the thermal stress produced within the structure; the restraint conditions of the adjacent parts and the long term loads. From these aspects, the 2D analyses of the thermal deflection behavior have been conducted on the fire response of planar frames[2]-[4].

However, the influence of the floor slab in a fire compartment exposed to fire, on the building structure can be significant, and may result in a propagation of fire to the upper floors or the collapse of the building itself. Therefore, it is more natural to analyze the stress-deformation behavior during a fire, with a 3D frame structure taking the effect of the floor slab into consideration. In studying the fire response of a building structure, it is necessary to take the following points into account:

(1) The floor slab, a separating component exposed directly to fire, will expand at earlier stages of the fire in comparison with the columns and beams protected from fire. It may, in fact, cause a large influence on the columns and beams.

(2) The columns, which are the structural components, will receive outward forces from the beams and floor slab in two directions in the horizontal plane.

(3) The floor slab and the beams within the fire compartment may produce larger deformations due to the bending effect induced by the temperature gradient within the floor slab. Note that this large deformation is not predictable in $2 \mathrm{D}$ analysis.

A floor slab can be treated as a composite beam which has the effective breadth in $2 \mathrm{D}$ analysis, but it is difficult clearly to explain the bending effect due to the temperature gradient within the floor slab in the orthogonal direction. Therefore, it is suitable to use $3 \mathrm{D}$ analysis to take account of the thermal expansion of a floor slab. In this study, in order to analyze the fire response of 3D steel frames of high-rise buildings exposed to compartment fire, first, a method of stress-deformation analysis concerning 3D steel frames exposed to fire has been established according to the following treatments: the problem of the increase in the number of nodes, which occurs in the 3D analysis taking account of the slab, has been treated by dividing the entire structural frame into unitary substructures; the thermal expansion of the floor slab is taken into account by conceiving the slab as a grid of intersecting beams; and a system of 3D coordinate transformation is formulated to track the movement of the Principal Axis of Section of a member due to the fire. The result of the analysis is then compared with the result of a large full-scale fire test[5] to verify the validity of the analytical method proposed in the current study. 


\section{ESTABLISHMENT OF A METHOD OF THERMAL STRESS-DEFORMATION ANALYSIS}

\subsection{Formulation of the End Restraint Forces and Adjacent Substructure Displacements}

The influence of fire should be kept local if the fire compartments work effectively[6]. Regarding the local characteristic of a fire incident, the entire structure, as shown in Figure 1, is divided into substructures: a local substructure; the adjacent structures; and the surrounding structures. A local substructure is the part that will be exposed to fire directly. Therefore, it is a part where a large plastic deformation is expected. An adjacent substructure will be affected by the thermal expansion of the local structure. However, the influence of fire in this region is considered to remain elastic. The surrounding substructure that comprises most parts of the building is a part where the influence of fire is extremely small.

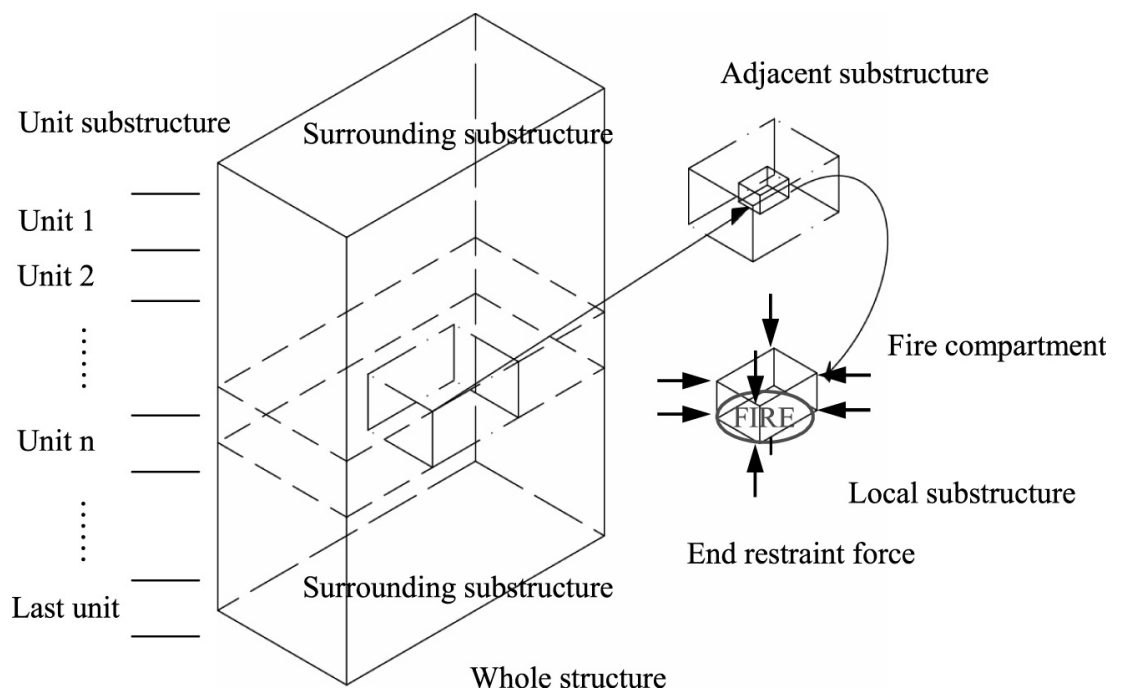

Figure 1 Dividing the Structure and Unit Substructure

In this section, the entire building will be divided into unitary substructures within each floor, as an approach to the problem of the increase in the number of nodes which occurs in the 3D analysis taking account of the slab. Then, the equations calculating the end restraint forces acting on the local substructure and the displacements of the adjacent substructures are formulated through contracting the resulting tensor sequentially, using the continuities in the forces and the displacements between the floors above and below[7]. 


\subsubsection{Equation Denoting the Balance of Force on a Unit Substructure}

In general, a unit substructure consists of some parts of local, adjacent, and surrounding substructures, as shown in Figure 2. The known forces acting on the $\mathrm{n}^{\text {th }}$ unit substructure are: the nodal force ${ }^{n} p_{f}$ exerted from the vertical loads that exist within the local substructure; the similar nodal force ${ }^{n} p_{a}$ acting within the adjacent substructures; the similar nodal force ${ }^{n} p_{g}$ acting on the surrounding substructures; and the force ${ }^{n} p_{p}$ acting on the nodes of the last boundary (it locates on the top of the unit substructure and connects the upper unit substructure, as shown in Figure 2). The unknown forces are the end restraint force ${ }^{n} R_{f}$ and the transferred forces ${ }^{n} R_{p}$ and ${ }^{n} R_{s}$ acting on the last and the next boundaries respectively. Considering the balance of force on each of the nodes, the balance equation for the $\mathrm{n}^{\text {th }}$ unit substructure will be given as follows:

$$
\left\{\begin{array}{c}
{ }^{n} P_{f} \\
{ }^{n} P_{a} \\
{ }^{n} P_{g} \\
{ }^{n} P_{p} \\
{ }^{n} 0_{s}
\end{array}\right\}=\left[\begin{array}{ccccc}
{ }^{n} K_{f, f} & { }^{n} K_{f, a} & 0 & { }^{n} K_{f, p} & { }^{n} K_{f, s} \\
{ }^{n} K_{a, f} & { }^{n} K_{a, a} & { }^{n} K_{a, g} & { }^{n} K_{a, p} & { }^{n} K_{a, s} \\
0 & { }^{n} K_{g, a} & { }^{n} K_{g, g} & { }^{n} K_{g, p} & { }^{n} K_{g, s} \\
{ }^{n} K_{p, f} & { }^{n} K_{p, a} & { }^{n} K_{p, g} & { }^{n} K_{p, p} & { }^{n} K_{p, s} \\
{ }^{n} K_{s, f} & { }^{n} K_{s, a} & { }^{n} K_{s, g} & { }^{n} K_{s, p} & { }^{n} K_{s, s}
\end{array}\right]\left\{\begin{array}{c}
{ }^{n} U_{f} \\
{ }^{n} U_{a} \\
{ }^{n} U_{g} \\
{ }^{n} U_{p} \\
{ }^{n} U_{s}
\end{array}\right\}+\left\{\begin{array}{c}
0 \\
0 \\
0 \\
-{ }^{n} R_{p} \\
-{ }^{n} R_{s}
\end{array}\right\}+\left\{\begin{array}{c}
+{ }^{n} R_{f} \\
0 \\
0 \\
0 \\
0
\end{array}\right\}
$$

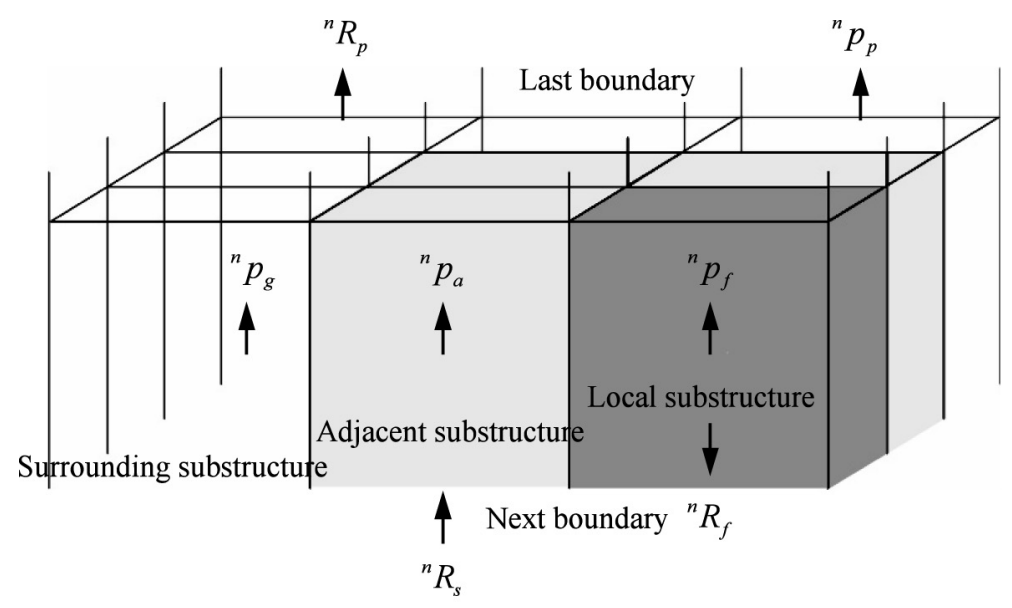

Unit substructure

Figure 2 Forces Acting on a Unit Substructure

Force:

$R_{p}: \quad$ Force transferred through the last boundary

$R_{s}$ : Force transferred through the next boundary

$R_{f}$ : $\quad$ End restraint force

$P_{a}: \quad$ Nodal force of an adjacent substructure

$P_{g}: \quad$ Nodal force of a surrounding substructure

$P_{p}: \quad$ Nodal force of acting on the last boundary

$P_{f}$ : Nodal force acting on a local substructure 


\section{Subscript:}

f : $\quad$ Boundary node between a local substructure and an adjacent substructure

a: Nodal point of an adjacent substructure

g: Nodal point of a surrounding substructure

$\mathrm{p}$ : Nodal point of the last substructure

$\mathrm{s}$ : Nodal point of the next substructure

$\mathrm{n}$ : Arbitrary unit substructure

\subsubsection{Force Transferred Through the Last Boundary}

The division of the structure is conducted from the top floor down to the bottom floor. The transferred force ${ }^{1} R_{p}$ acting on a unit substructure on the top floor is zero. Substituting this force into Equation 1, sweeping the matrix using the diagonal terms ${ }^{l} K_{a, a}{ }^{l} K_{g, g}{ }^{l} K_{p, p}$ of the $2^{\text {nd }}, 3^{\text {rd }}$, and $4^{\text {th }}$ lines of Equation 1, and repeating this manipulation of interior point elimination until a unit matrix is obtained will yield Equation 2.

$$
\left\{\begin{array}{c}
{ }^{1} P_{f}^{\prime} \\
{ }^{1} P_{a}^{\prime} \\
{ }^{1} P_{g}^{\prime} \\
{ }^{1} P_{p}^{\prime} \\
{ }^{1} P_{s}^{\prime}
\end{array}\right\}=\left[\begin{array}{ccccc}
{ }^{1} K_{f, f}^{\prime} & 0 & 0 & 0 & { }^{1} K_{f, s}^{\prime} \\
{ }^{1} K_{a, f}^{\prime} & I & 0 & 0 & { }^{1} K_{a, s}^{\prime} \\
{ }^{1} K_{g, f}^{\prime} & 0 & I & 0 & { }^{1} K_{g, s}^{\prime} \\
{ }^{1} K_{p, f}^{\prime} & 0 & 0 & I & { }^{1} K_{p, s}^{\prime} \\
{ }^{1} K_{s, f}^{\prime} & 0 & 0 & 0 & { }^{1} K_{s, s}^{\prime}
\end{array}\right]\left\{\begin{array}{c}
{ }^{1} U_{f} \\
{ }^{1} U_{a} \\
{ }^{1} U_{g} \\
{ }^{1} U_{p} \\
{ }^{1} U_{s}
\end{array}\right\}+\left\{\begin{array}{c}
0 \\
0 \\
0 \\
0 \\
-{ }^{1} R_{s}
\end{array}\right\}+\left\{\begin{array}{c}
+{ }^{1} R_{f} \\
0 \\
0 \\
0 \\
0
\end{array}\right\}
$$

From the $5^{\text {th }}$ line of Equation 2, the transferred force ${ }^{l} R_{s}$ working on the next boundary of the $1^{\text {st }}$ unit substructure can be expressed as follows:

$$
\left.\left\{{ }^{1} R_{s}\right\}=-\left\{{ }^{1} P_{s}^{\prime}\right\}+\left[{ }^{1} K_{s, f}^{\prime} \quad{ }^{1} K_{s, s}^{\prime}\right][]^{1} U_{f}{ }^{1} U_{s}\right\}^{T}
$$

Since there are continuities in the forces and the displacements through the next boundary of the $1^{\text {st }}$ unit substructure and the last boundary of the $2^{\text {nd }}$ unit substructure, the following equation can be obtained:

$$
\left\{\begin{array}{l}
{ }^{1} R_{s}=-{ }^{2} R_{p} \\
{ }^{1} U_{s}={ }^{2} U_{p}
\end{array}\right.
$$

Since ${ }^{1} U_{f}$ is included in ${ }^{2} U_{f}$, substituting Equation 4 into Equation 3 will produce Equation 5:

$$
\left.\left\{-{ }^{2} R_{p}\right\}=\left\{{ }^{1} R_{s}\right\}=-\left\{{ }^{1} P_{s}^{\prime}\right\}+\left[{ }^{1} K_{s, f}^{\prime \prime} \quad{ }^{1} K_{s, s}^{\prime}\right]\{\}^{2} U_{f} \quad{ }^{2} U_{p}\right\}^{T}
$$

By repeating this interior point elimination procedure, the force ${ }^{n} R_{p}$ transferred from the last boundary acting on the $\mathrm{n}^{\text {th }}$ unit substructure can be expressed with the following equation:

$$
\left.\left.\left\{-{ }^{n} R_{p}\right\}=\left\{{ }^{n-1} R_{s}\right\}=-\left\{{ }^{n-1} P_{s}^{\prime}\right\}+\left[{ }^{n-1} K_{s, f}^{\prime \prime} \quad{ }^{n-1} K_{s, s}^{\prime}\right]\right\}^{n} U_{f} \quad{ }^{n} U_{p}\right\}^{T}
$$




\subsubsection{The End Restraint Force, Adjacent Substructure Displacement, and Transferred Force Acting on an Arbitrary Substructure}

Substituting the force transferred from the last boundary shown in Equation 6 in Equation 1, the following equation is obtained:

$$
\left\{\begin{array}{c}
{ }^{n} P_{f} \\
{ }^{n} P_{a} \\
{ }^{n} P_{g} \\
{ }^{n} P_{p}-{ }^{n-1} P_{s}^{\prime} \\
{ }^{n} 0_{s}
\end{array}\right\}=\left[\begin{array}{ccccc}
{ }^{n} K_{f, f} & { }^{n} K_{f, a} & 0 & { }^{n} K_{f, p} & { }^{n} K_{f, s} \\
{ }^{n} K_{a, f} & { }^{n} K_{a, a} & { }^{n} K_{a, g} & { }^{n} K_{a, p} & { }^{n} K_{a, s} \\
0 & { }^{n} K_{g, a} & { }^{n} K_{g, g} & { }^{n} K_{g, p} & { }^{n} K_{g, s} \\
{ }^{n} K_{p, f}+{ }^{n-1} K_{s, f}^{\prime \prime} & { }^{n} K_{p, a} & { }^{n} K_{p, g} & { }^{n} K_{p, p}+{ }^{n-1} K_{s, s}^{\prime} & { }^{n} K_{p, s} \\
{ }^{n} K_{s, f} & { }^{n} K_{s, a} & { }^{n} K_{s, g} & { }^{n} K_{s, p} & { }^{n} K_{s, s}
\end{array}\right]\left\{\begin{array}{l}
{ }^{n} U_{f} \\
{ }^{n} U_{a} \\
{ }_{g} \\
{ }^{n} U_{p} \\
{ }^{n} U_{s}
\end{array}\right\}+\left\{\begin{array}{c}
0 \\
0 \\
0 \\
0 \\
0 \\
-{ }^{n} R_{s}
\end{array}\right\}+\left\{\begin{array}{c}
+{ }^{n} R_{f} \\
0 \\
0 \\
0 \\
0
\end{array}\right\}
$$

In Equation 7, ${ }^{n} R_{p}$ shows the accumulation of end restraint forces acting on the local substructures up to the $\mathrm{n}^{\text {th }}$ unit substructure. In this balance equation, by performing interior point elimination operations as the same as section 2.1.2, using the lines that do not include unknown forces, namely, lines 2,3 , and 4 , the following equation can be obtained:

$$
\left\{\begin{array}{c}
{ }^{n} P_{f}^{\prime} \\
{ }^{n} P_{a}^{\prime} \\
{ }^{n} P_{g}^{\prime} \\
{ }^{n} P_{p}^{\prime} \\
{ }^{n} P_{s}^{\prime}
\end{array}\right\}=\left[\begin{array}{ccccc}
{ }^{n} K_{f, f}^{\prime} & 0 & 0 & 0 & { }^{n} K_{f, s}^{\prime} \\
{ }^{n} K_{a, f}^{\prime} & I & 0 & 0 & { }^{n} K_{a, s}^{\prime} \\
{ }^{n} K_{g, f}^{\prime} & 0 & I & 0 & { }^{n} K_{g, s}^{\prime} \\
{ }^{n} K_{p, f}^{\prime} & 0 & 0 & I & { }^{n} K_{p, s}^{\prime} \\
{ }^{n} K_{s, f}^{\prime} & 0 & 0 & 0 & { }^{n} K_{s, s}^{\prime}
\end{array}\right]\left\{\begin{array}{c}
{ }^{n} U_{f} \\
{ }^{n} U_{a} \\
{ }^{n} U_{g} \\
{ }^{n} U_{p} \\
{ }^{n} U_{s}
\end{array}\right\}+\left\{\begin{array}{c}
0 \\
0 \\
0 \\
0 \\
0 \\
-{ }^{n} R_{s}
\end{array}\right\}+\left\{\begin{array}{c}
+{ }^{n} R_{f} \\
0 \\
0 \\
0 \\
0
\end{array}\right\}
$$

The $1^{\text {st }}, 2^{\text {nd }}$, and the $5^{\text {th }}$ lines of Equation 8 represent the end restraint forces, the displacements of the adjacent substructures, and the transferred forces respectively. These forces can be expressed with the following Equations 9-11.

End restraint force:

$$
\left.\left.\left\{{ }^{n} R_{f}\right\}=\left\{{ }^{n} P_{f}^{\prime}\right\}-\left[{ }^{n} K_{f, f}^{\prime} \quad{ }^{n} K_{f, s}^{\prime}\right]\right]{ }^{n} U_{f} \quad{ }^{n} U_{s}\right\}^{T}
$$

Displacements of the adjacent substructures:

$$
\left\{{ }^{n} U_{a}\right\}=\left\{{ }^{n} P_{a}^{\prime}\right\}-\left[{ }^{n} K_{a, f}^{\prime} \quad{ }^{n} K_{a, s}^{\prime}\right]\left[{ }^{n} U_{f} \quad{ }^{n} U_{s}\right\}^{T}
$$

Transferred forces acting on the next boundary:

$$
\left\{{ }^{n} R_{s}\right\}=-\left\{{ }^{n} P_{s}^{\prime}\right\}+\left[{ }^{n} K_{a, f}^{\prime} \quad{ }^{n} K_{s, s}^{\prime}\right]\left[{ }^{n} U_{f} \quad{ }^{n} U_{s}\right\}^{T}
$$

\subsubsection{Final Unit Substructure}

Repeating these operations described above successively, the final $\mathrm{L}^{\text {th }}$ unit substructure will be reached. The next boundary of the bottom unit substructure is restrained with fixed bases or pins. Therefore, most of the elements of ${ }^{L} U_{s}$ (displacement of the next boundary) are zero, and in case the substructure is restrained with pins, the value of the nodal forces will be zero, and hence, using the method of interior point 
elimination, the stiffness term of the unknown displacement can be made to become zero. Therefore, the end restraint forces and displacements of the adjacent substructure will be only those due to the displacement of the local substructure, and they can be expressed as the following Equations 12-13

End restraint force:

$$
\left\{{ }^{L} R_{f}\right\}=\left\{{ }^{L} P_{f}^{\prime}\right\}-\left[{ }^{L} K_{f, f}^{\prime}\right]\left[{ }^{L} U_{f}\right\}
$$

Displacements of the adjacent substructures:

$$
\left\{{ }^{L} U_{a}\right\}=\left\{{ }^{L} P_{a}^{\prime}\right\}-\left[{ }^{L} K_{a, f}^{\prime}\right]\left[{ }^{L} U_{f}\right\}
$$

\subsection{Estimation of the Stiffness of the Floor Slab}

The degradation of the material due to the exposure to heat and the elongation due to the thermal expansion will cause the members exposed directly to fire to exhibit relatively large stresses and deformations that exceed the limits of elastic region and enter the plastic region. In this paper, it is considered that the cross-section of a structural member will remain within the original plane after the deformation, and the cross-section will be divided into parts in order to take the effect of material nonlinear characteristic into account. Using the Tangent Stiffness Method based on the Infinitesimal Displacement Theory, a convergent calculation will be made, and hence, the value for the incremental displacement will be obtain. Accumulating these incremental displacements will take the effect of geometric nonlinear characteristic into account. The effect of the floor slab will be taken into account in the analysis as follows:

\subsubsection{Model Used to Line-Replace the Floor Slab}

As shown in Figure 3, there are two models that can be considered for the evaluation of a floor slab supported by beams on the surrounding edges: the "Planar Member Model" that divides the slab into two-dimensional finite elements, and the "Linear Member Model" that introduces cord elements such as grid beams.

Normally, the decision would be to adopt the planar member model, however, for the current study there was no basic data available on concrete placed under two-dimensional stresses at high temperatures. It also provides that the temperature difference between the heated surface and the unheated surface of the floor slab exposed to fire will be extremely large, so that a large bending moment and an axial force will be produced within the floor slab restrained at the ends[8]. The main factors of the effect of the slab on the structural frame will be the bending and expanding deformations of the slab, and the effect of shear deformation of the slab will be of secondary importance. Therefore, in this study, the main focus will be placed on the elongation of the floor slab due to thermal expansion and the bending effect due to the difference in the temperatures. As shown in Figure 4, the floor slab is line-replaced with grid beams as 
approximately, in order to take the effect of the heated floor slab into account.

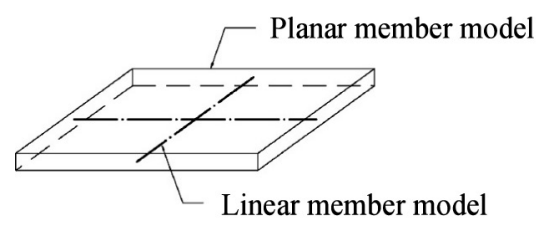

Figure 3 Model Used for the Floor Slab

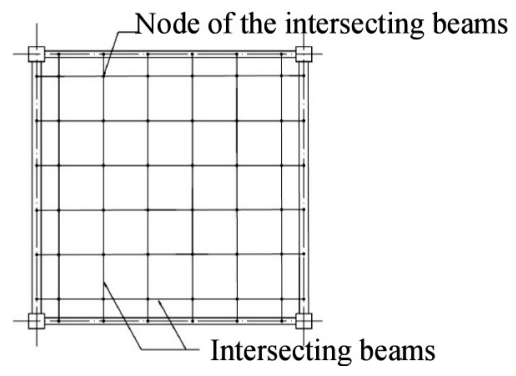

Figure 4 Line-Replacement of the Floor

\subsubsection{Stiffness of the Linear Member under High Temperature about its Principal Axis of Section}

A simplified Equation (14a) for the stiffness matrix sorted by each factor is used to calculate the stiffness of a linear member about its principal axis of section[9]. As illustrated later in Figure 6, the suffixes $\zeta$ and $\eta$ used in this equation signify the principal axis of section at high temperature. The Wagner twist is omitted in this equation.

$[\bar{K}]=\left[\begin{array}{cccccccccccc}E A / l & 0 & 0 & 0 & 0 & 0 & -E A / l & 0 & 0 & 0 & 0 & 0 \\ 0 & 12 E I_{\zeta} / l^{3} & 0 & 0 & 0 & 6 E I_{\zeta} / l^{2} & 0 & -12 E I_{\zeta} / l^{3} & 0 & 0 & 0 & 6 E I_{\zeta} / l^{2} \\ 0 & 0 & 12 E I_{\eta} / l^{3} & 0 & -6 E I_{\eta} / l^{2} & 0 & 0 & 0 & -12 E I_{\eta} / l^{3} & 0 & -6 E I_{\eta} / l^{2} & 0 \\ 0 & 0 & 0 & G J / l & 0 & 0 & 0 & 0 & 0 & -G J / l & 0 & 0 \\ 0 & 0 & -6 E I_{\eta} / l^{2} & 0 & 4 E I_{\eta} / l & 0 & 0 & 0 & 6 E I_{\eta} / l^{2} & 0 & 2 E I_{\eta} / l & 0 \\ 0 & 6 E I_{\zeta} / l^{2} & 0 & 0 & 0 & 4 E I_{\zeta} / l & 0 & -6 E I_{\zeta} / l^{2} & 0 & 0 & 0 & 2 E I_{\zeta} / l \\ -E A / l & 0 & 0 & 0 & 0 & 0 & E A / l & 0 & 0 & 0 & 0 & 0 \\ 0 & -12 E I_{\zeta} / l^{3} & 0 & 0 & 0 & -6 E I_{\zeta} / l^{2} & 0 & 12 E I_{\zeta} / l^{3} & 0 & 0 & 0 & -6 E I_{\zeta} / l^{2} \\ 0 & 0 & -12 E I_{\eta} / l^{3} & 0 & 6 E I_{\eta} / l^{2} & 0 & 0 & 0 & 12 E I_{\eta} / l^{3} & 0 & 6 E I_{\eta} / l^{2} & 0 \\ 0 & 0 & 0 & -G J / l & 0 & 0 & 0 & 0 & 0 & G J / l & 0 & 0 \\ 0 & 0 & -6 E I_{\eta} / l^{2} & 0 & 2 E I_{\eta} / l & 0 & 0 & 0 & 6 E I_{\eta} / l^{2} & 0 & 4 E I_{\eta} / l & 0 \\ 0 & 6 E I_{\zeta} / l^{2} & 0 & 0 & 0 & 2 E I_{\zeta} / l & 0 & -6 E I_{\zeta} / l^{2} & 0 & 0 & 0 & 4 E I_{\zeta} / l\end{array}\right]$

However, the coefficients in Equation $14 a$ for the stiffness of linear member with the principal axis of section at elevated temperature will be given by:

$$
\left\{\begin{array}{l}
E A=\int E_{t} d A=\sum E_{t} \Delta A \\
E I_{\zeta}=\int E_{t} \eta^{2} d A=\sum E_{t} \eta^{2} \Delta A \\
E I_{\eta}=\int E_{t} \zeta^{2} d A=\sum E_{t} \zeta^{2} \Delta A \\
G J=J \cdot \frac{\int G_{t} d A}{\int d A}=J \cdot \frac{\sum G_{t} \Delta A}{\sum \Delta A}
\end{array}\right.
$$

Here, $E_{t}$ in the equation expresses Young's modulus of part in the section of a member or a tangent modulus at each level of temperature, it will change with time. 


\subsubsection{Stiffness Matrix of the Member about its Reference Axis}

Concerning the line-replaced floor slab and beams, the balance of force is calculated along the reference axis that penetrates the geometrical center of the beam to calculate the incremental deformation of the individual members, as shown in Figure 5. The distance from the line-replaced floor slab to the reference axis shall be calculated using Equation 15 as illustrated in Figure 6.

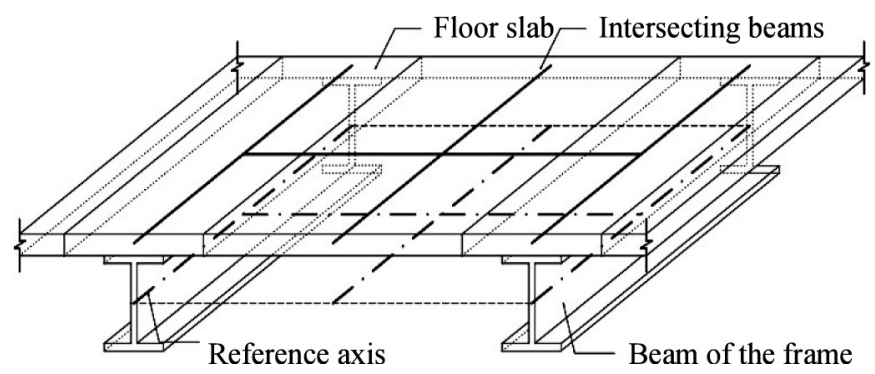

Figure 5 Calculation Model for the Floor Slab

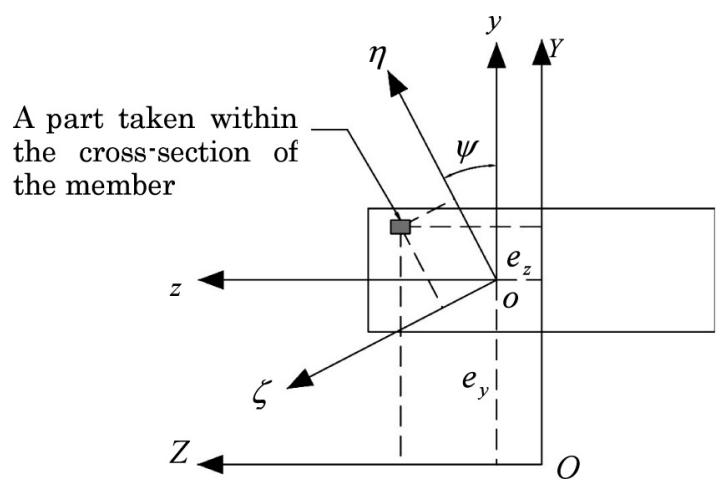

Figure 6 Relationship Between the Reference Axis [Y,O,Z] and the Principal Axis under High Temperature $[\eta, o, \zeta]$

$$
\left\{\begin{array}{l}
e_{y}=\int E_{t} Y d A / \int E_{t} d A \\
e_{z}=\int E_{t} Z d A / \int E_{t} d A \\
\tan 2 \psi=-2 \int E_{t} y z d A /\left(\int E_{t} z^{2} d A-\int E y^{2} d A\right)
\end{array}\right.
$$

In this equation, $E_{t}$ is the Young's modulus or the Tangent Coefficient at each increase of temperature for the part taken within the cross-section of the member, it will change with time.

The following equation describes the relationship between the incremental force at the end of the member along the principal axis of section at high temperature $\{\overline{\bar{F}}\}$ and the stiffness matrix of the member $\{\overline{\bar{K}}\}$ and the incremental displacement at the end of the member $\{\overline{\bar{\delta}}\}$ : 


$$
\{\overline{\bar{F}}\}=[\overline{\bar{K}}]\{\overline{\bar{\delta}}\}
$$

The relationship between the incremental displacement at the end of the member along the principal axis of section at high temperature $\{\overline{\bar{\delta}}\}$ and the incremental displacement at the end of the member along the reference axis $\{\bar{\delta}\}$ is determined by Equation 17:

$$
\{=[\bar{\delta}\}=[H]\{\bar{\delta}\}
$$

In this equation, $[H]$ is given as follows:

$$
\begin{aligned}
& {[H]=\left[\begin{array}{ll}
A & 0 \\
0 & A
\end{array}\right]} \\
& A=\left[\begin{array}{cccccc}
1 & 0 & 0 & 0 & +e_{z} & -e_{y} \\
0 & +\lambda & +\mu & -e_{z} \lambda+e_{y} \mu & 0 & 0 \\
0 & -\mu & +\lambda & +e_{z} \mu+e_{y} \lambda & 0 & 0 \\
0 & 0 & 0 & 1 & 0 & 0 \\
0 & 0 & 0 & 0 & +\lambda & +\mu \\
0 & 0 & 0 & 0 & -\mu & +\lambda
\end{array}\right] \\
& \lambda=\cos \psi, \mu=\sin \psi
\end{aligned}
$$

Since both the virtual works of the external forces along the principal axis of section at high temperature and the reference axis are equal with the similar virtual work for internal force, the following equation can be obtained:

$$
\left\{=\bar{\delta}^{T}\{\overline{\bar{F}}\}=\{\bar{\delta}\}^{T}\{\bar{F}\}\right.
$$

Substituting Equation 16 and Equation 17 into Equation 19, the member stiffness matrix $[\bar{K}]$ about its reference axis is given as follows:

$$
[\bar{K}]=[H]^{T}[\overline{\bar{K}}][H]
$$

\subsection{Formulation of Coordinate Transformation Equation in Three-Dimensional Space}

In addition to the parallel and rotational movements, the movement of a member exposed to fire in three-dimensional space will also be composed of axial rotation around the axis of the member. The principal axis of section may change following a rotational movement of the member, depending on the trajectory of rotation that the member will take. Therefore, the amount of the rotational angle of the principal axis of section of the member is determined as a sum of the rotational angle around the axis of the member and the rotational angle of the principal axis of section depending on the trajectory of the rotating movement of the member. 
In general, the coordinate transformation in three-dimensional space is given by Equation 21:

$$
\left\{\begin{array}{l}
x \\
y \\
z
\end{array}\right\}=\left[\begin{array}{lll}
\cos x X & \cos x Y & \cos x Z \\
\cos y X & \cos y Y & \cos y Z \\
\cos z X & \cos z Y & \cos z Z
\end{array}\right]\left\{\begin{array}{l}
X \\
Y \\
Z
\end{array}\right\}
$$

Here, $\cos x X$ is defined as the direction cosine between the axis of the Local Coordinate System (described later in detail) and the $X$ axis of the Global Coordinate System. $y, z, Y, Z$ are defined likewise.

In this study, Equation 21 providing the coordinate transformation at each step of the calculation times is derived as follows:

\subsubsection{Relationship between the Global Coordinate System and the Local Coordinate System}

The coordinate systems used in this section are defined as illustrated in Figure 7. The global coordinate system $[X, Y, Z]$ is a common coordinate system applied throughout the building. The local coordinate system $[x, y, z]$ is defined using the right-hand rule, in a way such that the $x$ axis is taken along the length of the component, and the $y$ and $z$ axis are taken to coincide with the principle axis of section of the component. The referential coordinate system $\left[x, y_{r}, z_{r}\right]$ is determined so that the direction $O_{i} C$ in Plane $A B C$ vertical to the $x$ axis of the component is chosen as the $z_{r}$ axis, and the $y_{r}$ axis will be chosen to form an orthogonal system in accordance with the right-hand rule. Here, the direction of the $z_{r}$ axis is chosen in the direction that the $Z$ component (in the global coordinate system) will increase. The angle from the $z_{r}$ axis to the $z$ axis will be determined as $\theta$ using the right-hand rule to determine the positive direction, and the angle $\theta$ is called the amount of the rotational angle of the principal axis of section.

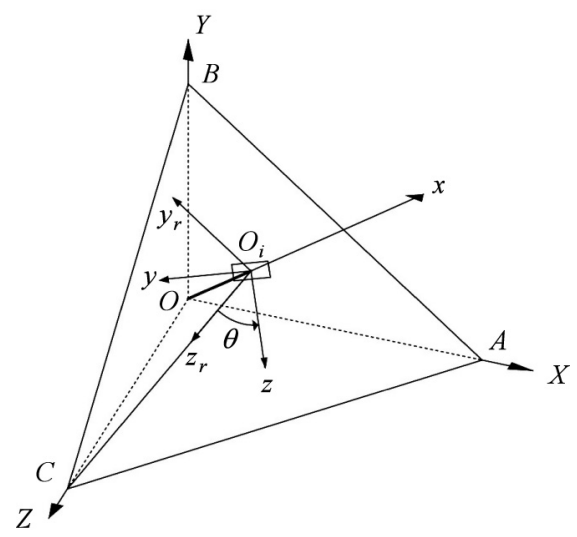

Figure 7 Relationship between the Local Coordinate System and the Global Coordinate System of a Column-Shaped Member 
Once $\theta$ is determined, the relationship between the Global Coordinate System $[X, Y, Z]$ and the Local Coordinate System $[x, y, z]$ can be determined using Pythagoras theorem as follows:

$$
\left\{\begin{array}{l}
x \\
y \\
z
\end{array}\right\}=\left[\begin{array}{ccc}
l & m & n \\
(-\lambda m-\mu n l) / \omega & (\lambda l-\mu m n) / \omega & \mu \omega \\
(\mu m-\lambda n l) / \omega & (-\mu l-\lambda m n) / \omega & \lambda \omega
\end{array}\right]\left\{\begin{array}{l}
X \\
Y \\
Z
\end{array}\right\}
$$

Here, $l=\cos \alpha, m=\cos \beta, n=\cos \gamma, \lambda=\cos \theta, \mu=\cos \theta, \omega=\sqrt{l^{2}+m^{2}}$. And, $\alpha, \beta, \gamma$ are the angles between the $x$ axis of the Local Coordinate System and the $X, Y, Z$ axis of the Global Coordinate System respectively.

In Equation 22, the coordinate transformation equation corresponding to $\omega=0$, in other words when the $x$ axis is parallel to the $z$ axis, is provided similarly with Equation 23, by moving the $y_{r}$ axis of the Referential Coordinate System illustrated in Figure 7 to point to the $Y$ axis of the Global Coordinate System.

$$
\left\{\begin{array}{l}
x \\
y \\
z
\end{array}\right\}=\left[\begin{array}{ccc}
l & m & n \\
(-\lambda m l-\mu n) / \omega & \lambda \omega & (\mu l-\lambda m n) / \omega \\
(\mu l m-\lambda n) / \omega & -\mu \omega & (\lambda l+\mu m n) / \omega
\end{array}\right]\left\{\begin{array}{l}
X \\
Y \\
Z
\end{array}\right\}
$$

Here, $l=\cos \alpha, m=\cos \beta, n=\cos \gamma, \lambda=\cos \theta, \mu=\cos \theta, \omega=\sqrt{l^{2}+n^{2}}$

\subsubsection{Estimation of the Rotation Angle of the Principal Axis of Section Depending on the Trajectory of the Rotational Movement of the Member}

As shown in Figure 8, it is considered that the member will move along the trajectory $S$ from the last position $\mathrm{OO}_{1}$ to the next position $\mathrm{OO}_{2}$. It is assumed that the member will not rotate around the $x$ axis in this movement process. Defining ${ }_{s} \theta_{i}$ as the angle between the $z_{r, i}(i=1,2)$ axis of the referential coordinate system and the tangent vector $S_{i}$ of the trajectory, and defining $\phi_{i}$ as the angle between the $z_{i}$ axis of the local coordinate system and the tangent vector $S_{i}$ of the trajectory, the following relation can be derived:

$$
\theta_{i}={ }_{s} \theta_{i}-\phi_{i}
$$

Since it is assumed that there will be no rotation around the $x$ axis, the angle $\phi_{i}$ will remain constant throughout the movement $\left(\phi_{1}=\phi_{2}\right)$. Therefore, the rotational angle $\theta_{2}$ of the principal axis of section after the rotation is derived as follows:

$$
\theta_{2}={ }_{s} \theta_{2}-\phi_{2}={ }_{s} \theta_{2}-\left({ }_{s} \theta_{1}-\theta_{1}\right)
$$




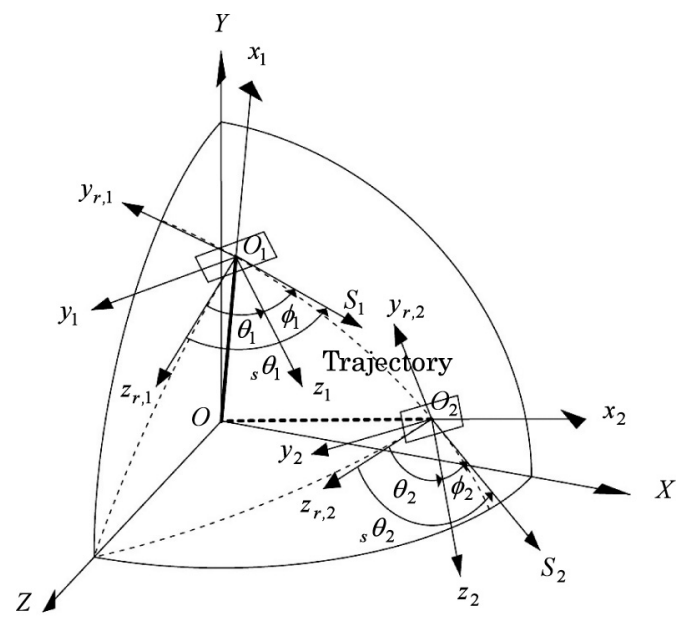

Figure 8 Rotation of the Principal Axis of Section Depending on the Trajectory of the Rotational Movement of the Member

The calculation scheme for the angle ${ }_{s} \theta_{i}$ from the $z_{r, i}$ axis of the Referential Coordinate System to the Trajectory Tangent Vector $S_{i}$ is provided in Table 1 [10].

Table 1 Calculation Scheme for the Angle ${ }_{s} \theta_{i}$ from the $z_{r, i}$ Axis of the Referential Coordinate System to the Trajectory Tangent Vector $S_{i}$

\begin{tabular}{|c|c|c|c|c|}
\hline \multicolumn{2}{|r|}{$n_{i}$} & $>0$ & $<0$ & $=0$ \\
\hline \multicolumn{2}{|r|}{$r_{i}$} & $-m_{i} w_{i}-\left(\frac{1}{n_{i}}-n_{i}\right) v_{i}$ & $\left(\frac{1}{n_{i}}-n_{i}\right) v_{i}+m_{i} w_{i}$ & $-v_{i}$ \\
\hline \multicolumn{2}{|r|}{$q_{i}$} & $l_{i} w_{i}+\left(\frac{1}{n_{i}}-n_{i}\right) u_{i}$ & $-\left(\frac{1}{n_{i}}-n_{i}\right) u_{i}-l_{i} w_{i}$ & $u_{i}$ \\
\hline \multicolumn{2}{|r|}{$t_{i}$} & $-l_{i} v_{i}+m_{i} u_{i}$ & $l_{i} v_{i}-m_{i} u_{i}$ & 0 \\
\hline \multirow{2}{*}{$A_{i}$} & $n_{i} \neq 0$ & $\sqrt{u_{i}^{2}+v_{i}^{2}+w_{i}^{2}} \cdot \sqrt{1-n_{i}^{2}}$ & \multicolumn{2}{|c|}{$\left(-l_{i} u_{i} n_{i}-m_{i} v_{i} n_{i}+\left(1-n_{i}^{2}\right) w_{i}\right)$} \\
\hline & $n_{i}=0$ & \multicolumn{2}{|r|}{$w_{i}$} & $\sqrt{u_{i}^{2}+v_{i}^{2}+w_{i}^{2}}$ \\
\hline \multirow[b]{3}{*}{${ }_{s} \theta_{i}$} & $A_{i}=+1$ & \multicolumn{3}{|c|}{0} \\
\hline & $A_{i}=-1$ & \multicolumn{3}{|c|}{$\pi$} \\
\hline & $A_{i} \neq \pm 1$ & \multicolumn{3}{|c|}{$\left(\frac{l_{i} r_{i}+m_{i} q_{i}+n_{i} t_{i}}{\sqrt{r_{i}^{2}+q_{i}^{2}+t_{i}^{2}}}\right) \cdot \arccos \left(A_{i}\right)$} \\
\hline
\end{tabular}

Similarly, the calculation scheme for the angle ${ }_{s} \theta_{i}$ from the $y_{r, i}$ axis of the Reference Coordinate System to the Trajectory Tangent Vector $S_{i}$ when the $x$ axis is parallel to the $Z$ axis (in other words, when $\omega=0$ ) is provided in Table 2 [10]. 
Table 2 Calculation Scheme for the Angle $\theta_{i} \theta_{i}$ from the $y_{r, i}$ Axis of the Reference Coordinate System to the Trajectory Tangent Vector $S_{i}$

\begin{tabular}{|c|c|c|c|c|}
\hline \multicolumn{2}{|c|}{$m_{i}$} & $>0$ & $<0$ & \multirow{2}{*}{$\begin{array}{l}=0 \\
w_{i}\end{array}$} \\
\hline & $r_{i}$ & $\left(\frac{1}{m_{i}}-m_{i}\right) w_{i}+n_{i} v_{i}$ & $\left(-\frac{1}{m_{i}}+m_{i}\right) w_{i}-v_{i} n_{i}$ & \\
\hline & $q_{i}$ & $-u_{i} n_{i}+l_{i} w_{i}$ & $n_{i} u_{i}-l_{i} w_{i}$ & 0 \\
\hline & $t_{i}$ & $-\left(\frac{1}{m_{i}}-m_{i}\right) u_{i}-l_{i} v_{i}$ & $l_{i} v_{i}+u_{i}\left(\frac{1}{m_{i}}-m_{i}\right)$ & $-u_{i}$ \\
\hline \multirow{2}{*}{$A_{i}$} & $m_{i} \neq 0$ & \multicolumn{3}{|c|}{$\frac{\left(-l_{i} u_{i} m_{i}-n_{i} w_{i} m_{i}+\left(1-m_{i}^{2}\right) v_{i}\right)}{\sqrt{u_{i}^{2}+v_{i}^{2}+w_{i}^{2}} \cdot \sqrt{1-m_{i}^{2}}}$} \\
\hline & $m_{i}=0$ & \\
\hline \multirow[b]{3}{*}{${ }_{s} \theta_{i}$} & $A_{i}=+1$ & \multicolumn{3}{|c|}{0} \\
\hline & $A_{i}=-1$ & \multicolumn{3}{|c|}{$\pi$} \\
\hline & $A_{i} \neq \pm 1$ & \multicolumn{3}{|c|}{$\operatorname{sgn}\left(\frac{l_{i} r_{i}+m_{i} q_{i}+n_{i} t_{i}}{\sqrt{r_{i}^{2}+q_{i}^{2}+t_{i}^{2}}}\right) \cdot \arccos \left(A_{i}\right)$} \\
\hline
\end{tabular}

\subsubsection{The Amount of the Rotational Angle of the Principal Axis of Section of the Member}

The Amount of the Rotational Angle of the Principal Axis of Section of the Member is determined as a sum of the rotational angle around the axis of the member and the rotational angle of the principal axis of section depending on the trajectory of the rotating movement of the member. Therefore, by adding the rotational angle around the axis of the member $\left(\theta_{x}\right)$ to the rotational angle of the principal axis of $\operatorname{section}\left(\theta_{2}\right)$ estimated using Equation 25, the amount of the rotational angle $\theta$ of the principal axis of section of the member at next position can be determined using the following equation:

$$
\theta=\theta_{2}+\theta_{x}={ }_{s} \theta_{2}-\left({ }_{s} \theta_{1}-\theta_{1}\right)+\theta_{x}
$$

Substituting Equation 26 into Equation 22 or Equation 23, the coordinate transformation between the Global Coordinate System and the Local Coordinate System can be formulated, taking into account the rotational angle of the principal axis of section depending on the trajectory of the rotating movement of the member.

\section{COMPARISON WITH A LARGE FULL-SCALE FIRE TEST}

An analysis was performed against the thermal deformation in a large full-scale fire test of 3-stories type car park[5], as shown in Figure 9 and 10(the beams and columns are thermally unprotected). The theoretical results were compared with those recorded in experiments. This fire test of 3-stories type car park was performed in order to 
confirm the behavior of the fire spreading from vehicles which caught fire in a large space with an assumed area of $4000 \mathrm{~m}^{2}$ per floor. There were 8 cars burnt in the fire test. The deformation of the portions that are strongly influenced by thermal expansion has been measured. In the following passages, the results of this large full-scale fire test are evaluated to verify the appropriateness of the analyzing method established in the current study.

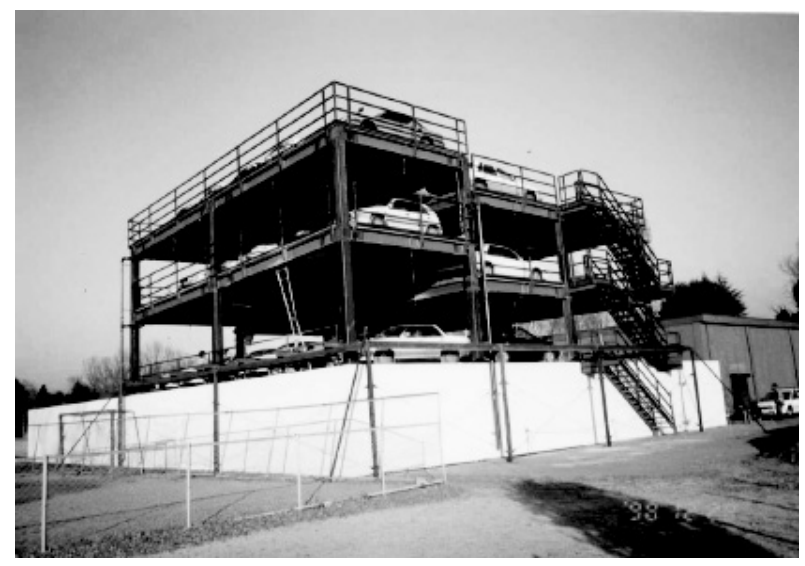

Figure 9 Structure used in the large full-scale fire test

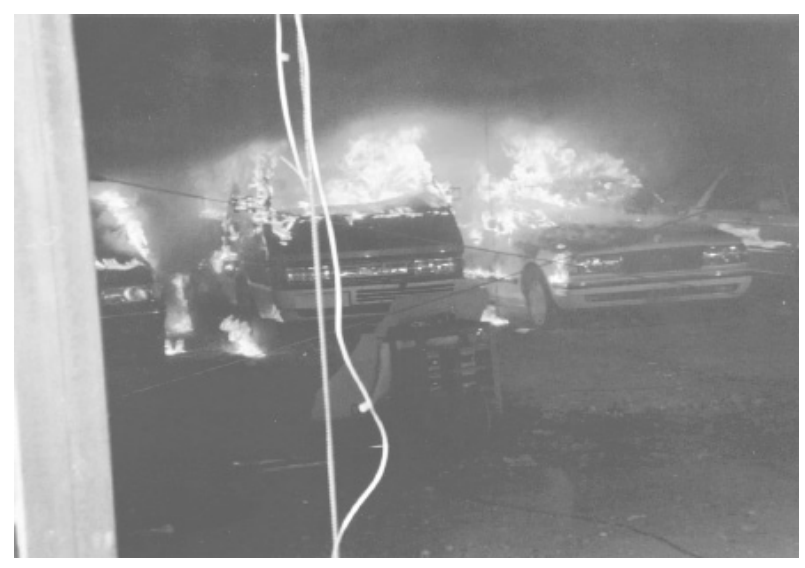

Figure 10 Vehicles on Fire

\subsection{Conditions of the Analysis}

\subsubsection{Analytical Structure}

The analysis will be performed on 3 stories portions of the car park (See Figure 11). Because the columns of the test structure are only mounted on top of two $\mathrm{H}$ shaped steel members, and the bases of some of the inner columns are restrained using high-strength bolts, the restraints at the base of the column of the $1^{\text {st }}$ floor are configured as shown in 
Figure 11, based on the measurements obtained in the experiment on the displacement at the bases of the columns. The columns on the $1^{\text {st }}$ floor and the floor slabs (shaded parts) and the beams on the $2^{\text {nd }}$ floor in the area bounded by (3)-(5) and (D)-(E) (see figure 11) are the members that have been exposed directly to vehicle fire. The weight placed on the floor is $4.8 \mathrm{kN}$ per square meter of floor slab. The $1^{\text {st }}$ floor portion of the structural frame is considered as the local substructure to the elasto-plastic analysis, and the $2^{\text {nd }}$ and $3^{\text {rd }}$ floors are considered as adjacent structures that will be treated elastically. Only the floor slabs that are directly exposed to vehicle fire (the shaded parts) will be included in the elasto-plastic analysis. A set of intersecting beams located approximately 1 meter apart from each other were adopted in the line-replacement of the floor slabs. Rigid joints were adopted to connect the line-replaced floor slabs to the beams sustaining the floor slabs. And, the composite action between the steel beams and the concrete slab is considered in the analytical model in part. The abstract diagram for the deck plate composite slab is shown on Figure 12. The cross-sectional dimensions of the members are shown in Table 3. The design standard strength of concrete is $21 \mathrm{~N} / \mathrm{mm}^{2}$.

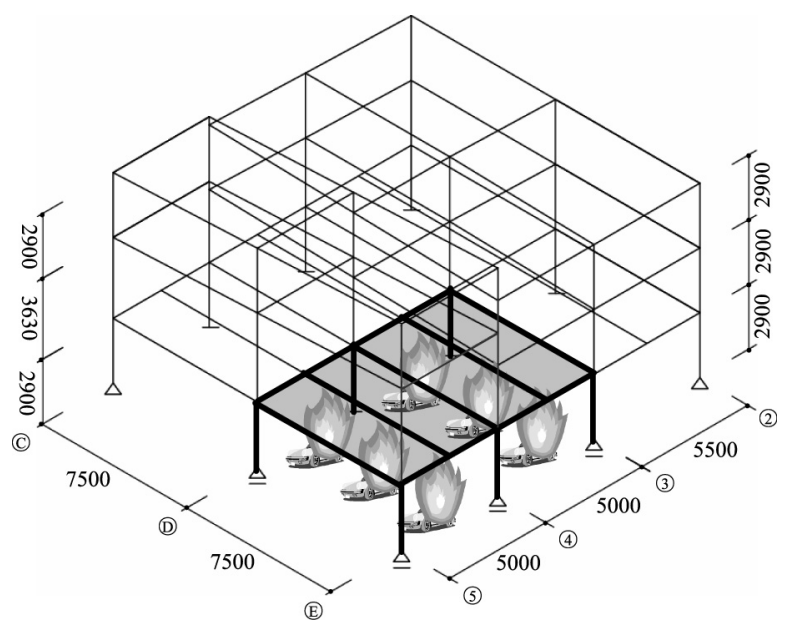

Figure 11 Model of the Structural Frame (unit: mm)

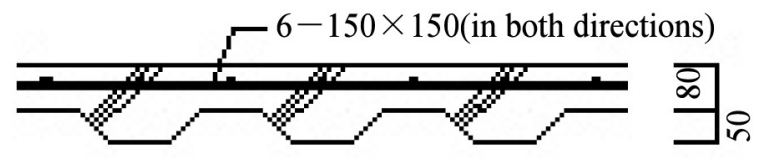

Deck plate for composite slab Wide-ditch gutter type $50 \quad t=1.2 \mathrm{~mm}$

Figure 12 Composite Slab 
Table 3 List of Structural Members (unit: $\mathrm{mm}$ )

\begin{tabular}{|c|c|c|}
\hline List of Cross Sections & $1^{\text {st }}$ Floor & $2^{\text {nd }}$ and $3^{\text {rd }}$ Floors \\
\hline Column & $\square-300 \times 300 \times 12$ & $\square-300 \times 300 \times 9$ \\
\hline Beam & \multicolumn{2}{|c|}{ H- $400 \times 200 \times 8 \times 13$} \\
\hline Small beam & H- $350 \times 175 \times 7 \times 11$ \\
\hline Floor Slab & h(Reduced Thickness $)=100$ \\
\hline
\end{tabular}

The replacement of the floor slab with linear elements is illustrated in Figure 13. The sections of linear elements are segmented into small parts at about $5 \mathrm{~mm}$ in height and one-fourth of the width of the linear elements in breadth as shown in Figure 14, and they are supposed to remain flat even after deformation.

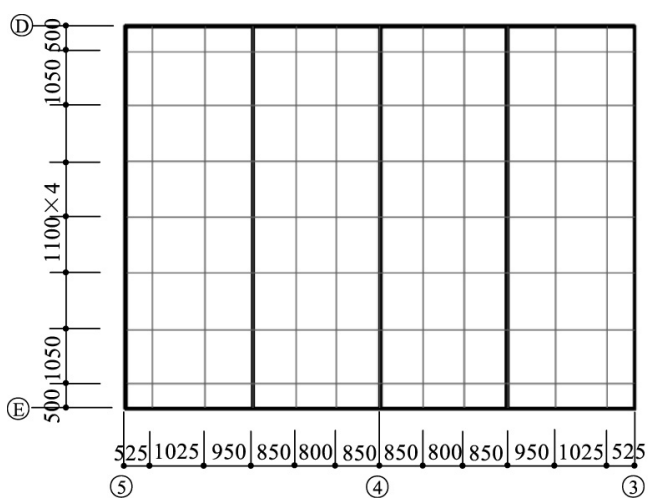

Figure 13 Floor Slabs Described with Linear Elements

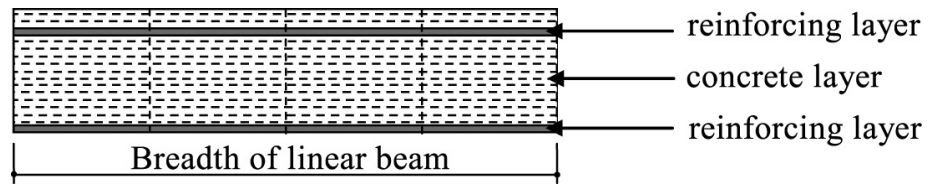

Figure 14 Split of Grid Beam of the Floor Slabs

\subsubsection{Temperatures of the Columns and Beams}

In the current analysis, the temperature values obtained from the large full-scale fire test are used for the members directly exposed to fire. The cross-section of each member is divided into parts according to its temperatures obtained in the experiment, a steel pipe column is divided into four parts, and an $\mathrm{H}$ shaped steel beam is divided into the web and the upper/lower flanges. An average temperature is calculated for each of the parts from the values obtained in the experiment along the axis of member, and the temperature of each part is regarded as uniformity along the axis of a member [11]. 
Figure 15 shows the temperature of the small beam supporting the floor "s1" bounded by (4)-(5) and (D)-(E), and the temperature of the column on the 1 st floor located (E) and (4). The maximum average temperature of the columns is about $260^{\circ} \mathrm{C}$, About $530^{\circ} \mathrm{C}$ is of the beams.

The temperatures of the columns and beams not directly exposed to fire are assumed to be equal to the room temperature.
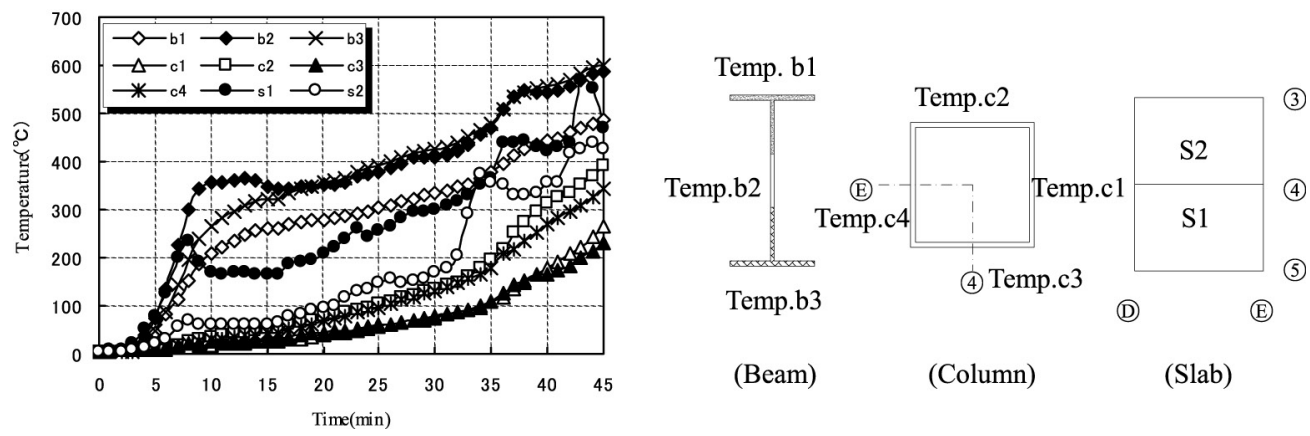

Figure 15 Transition of Temperatures in Some of the Structural Members Exposed to Fire

\subsubsection{Temperature Distribution in the Floor Slab}

As for the temperature distribution of the floor slab, the average value measured in the large full-scale fire test on the surface exposed to fire is used in the analysis as the temperature of the heated surface. The slab is divided into layers in the direction of its thickness, and the temperature of each layer is approximated using the following error function that provides the solution[12] for a semi-infinite body:

Temperature of each layer: $T=T_{s}+\left(T_{0}-T_{s}\right) \operatorname{erf}\left(\frac{x}{2 \sqrt{\alpha t}}\right)$

$T_{0}:$ Room temperature

$t$ : Heating time

$T_{s}$ : Temperature of the heated surface of the slab at time

$x$ : Distance from the heated surface of the slab to the center of each layer

$\alpha$ : thermometric conductivity of the floor slab

Figure 15 shows the temperatures for the heated surfaces of the floors $\mathrm{s} 1$ bounded by (4)-(5) and (D)-(E), and s2 bounded by (3)-(4) and (D)-(E) (the maximum average temperature for the heated surfaces of the floor slabs is about $440^{\circ} \mathrm{C}$ ). Figure 16 shows the analytical values and the experimental values for the temperatures of the unheated surfaces for floors s1 and s2. The temperature distribution within the floor slab should be determined precisely, taking the amount of contained water, and other factors into account. However, the main parameter governing the behavior of the floor slab is the temperature difference between the heated surface and the unheated surface. As shown in Figure 16, the differences between the analytical and the experimental values for the 
temperatures on the unheated surface in the current case are between 10 and $20^{\circ} \mathrm{C}$. The main target of the current study is to study the fire response of the structural frames, therefore, we will consider the influences of these temperature differences as to be small, and will adopt Equation 27 for the calculation of the temperature distribution within the floor slabs.

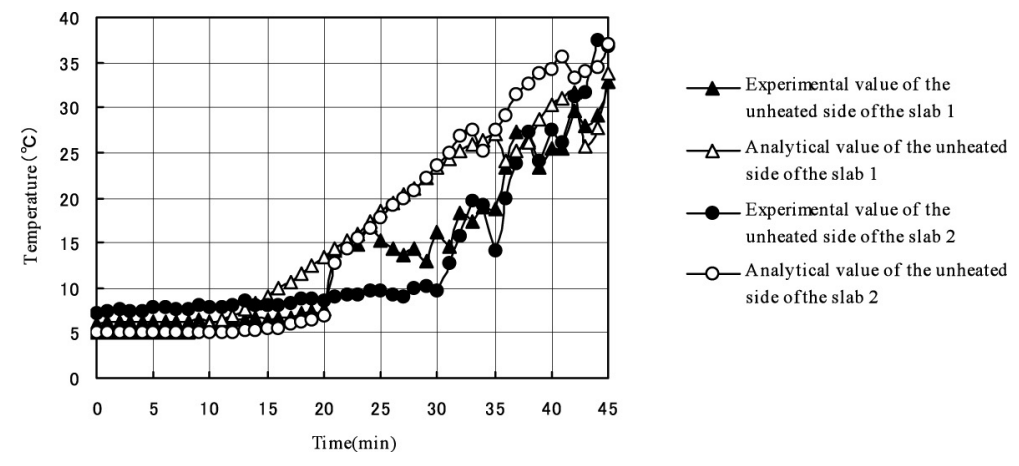

Figure 16 Transition of the Temperature on the Unheated Side of the Floor Slab

\subsubsection{Composition Rule for the Strain of Steel and Concrete at High Temperatures}

The total strain $\varepsilon$ of steel and concrete at high temperatures is defined as the sum of the strain caused by stress $\left(\varepsilon_{\sigma}\right)$ and the strain caused by thermal expansion $\left(\varepsilon_{t h}\right)$, and hence, transient strain $\left(\varepsilon_{t r}\right)$ is added to these factors in the case of concrete. The strain composition rule between steel and concrete is shown below:

Composition rule for steel members

$$
\begin{aligned}
& \varepsilon=\varepsilon_{\sigma}+\varepsilon_{t h} \\
& \varepsilon_{\sigma}=\sigma / E_{t}+\left(\sigma / \sigma_{k}\right)^{k} \\
& \varepsilon_{t h}=\left(10.8 T+0.00675 T^{2}\right) \times 10^{-6}
\end{aligned}
$$

The parameters $\sigma_{k}, k$, and $E_{t}$ are derived from the stress-strain curves formulated as exponential functions[15] through using the following two points. The first point is $0.2 \%$ offset point, and the second is that which strain is $30 \%$. In this analysis, the stress-strain curves are obtained from the tensile test at elevated temperature performed on the steel member used in the current large full-scale fire test. Figure 17 shows the stress-strain curves for the steel pipe columns used in the current experiment. The parameters $\sigma_{k}, k$, and $E_{t}$ determined from these curves are provided in Table 4. 


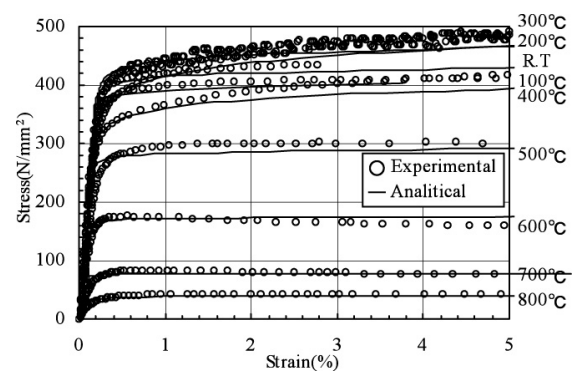

Figure 17 Stress-Strain Curves for Steel Pipe Columns ( $\square-300 \times 300 \times 12$ SS400)

Table 4 Values of $E_{t}, \sigma_{k}, k$

\begin{tabular}{|c|c|c|c|}
\hline Temp. & $E_{t}\left[\mathrm{~N} / \mathrm{mm}^{2}\right]$ & $\sigma_{k}\left[\mathrm{~N} / \mathrm{mm}^{2}\right]$ & $k$ \\
\hline Room Temp. & 202625 & 466.1 & 49.33 \\
\hline $100^{\circ} \mathrm{C}$ & 190004 & 435.4 & 55.58 \\
\hline $200^{\circ} \mathrm{C}$ & 180642 & 517.4 & 35.14 \\
\hline $300^{\circ} \mathrm{C}$ & 176777 & 578.7 & 15.63 \\
\hline $400^{\circ} \mathrm{C}$ & 171475 & 468.7 & 19.90 \\
\hline $500^{\circ} \mathrm{C}$ & 156216 & 314.4 & 55.77 \\
\hline $600^{\circ} \mathrm{C}$ & 107614 & 184.7 & 94.05 \\
\hline $700^{\circ} \mathrm{C}$ & 63450 & 86.1 & 71.47 \\
\hline $800^{\circ} \mathrm{C}$ & 31027 & 47.1 & 26.29 \\
\hline
\end{tabular}

Composition Rule for Concrete

$\varepsilon=\varepsilon_{\sigma}+\varepsilon_{t h}+\varepsilon_{t r}$

$\varepsilon_{\sigma}$ : Determined according to Eurocode No.4 [16] (See Figure 18)

$$
\begin{aligned}
& \varepsilon_{\text {th }}= \begin{cases}-1.8 \times 10^{-4}+9 \times 10^{-6} \times T+2.3 \times 10^{-11} \times T^{3} & \left(20^{\circ} \mathrm{C} \leqq T \leqq 700^{\circ} \mathrm{C}\right) \\
14.0 \times 10^{-3} & \left(700^{\circ} \mathrm{C}<T \leqq 1200^{\circ} \mathrm{C}\right)\end{cases} \\
& \varepsilon_{t r}=-2.35 \times \frac{\sigma_{T}}{\sigma_{R . T}} \times \varepsilon_{t h}
\end{aligned}
$$

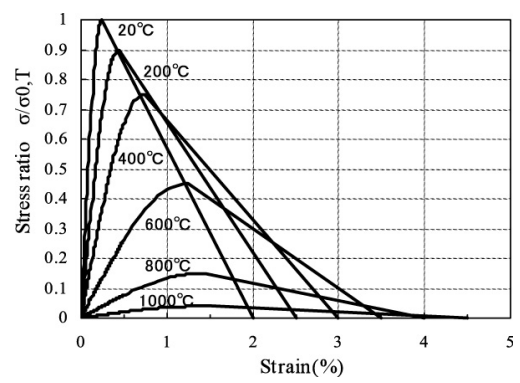

Figure 18 Stress-Strain Curves for Concrete at High Temperatures 


\subsection{Results of the Analysis and Considerations}

In the large full-scale fire test, fire-extinguishing activity began 42 minutes after ignition. In the present analysis, we will discuss the behavior of the frame during the heating process.

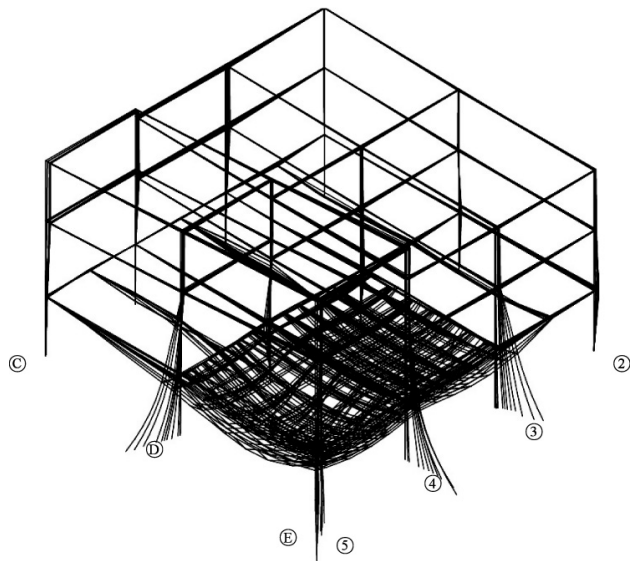

Figure 19 Thermal Deformation of the Structural Frame (30x magnification)

Figure 19 shows the thermal deformation of the structural frame during the heating process at 5 minutes interval. As shown in Figure 19, large deformations can be seen on the columns, beams, and the floors exposed to fire. It is assumed that roller supports are installed at the bases of the columns of the $1^{\text {st }}$ floor, therefore, the displacement at the bases of the columns of the $1^{\text {st }}$ floor, caused by the thermal elongation of the beams on the $2^{\text {nd }}$ floor exposed to fire, will be twice of the elongation of the beams. The beams and the floor slabs interact with each other to form a hammock-like deformation.

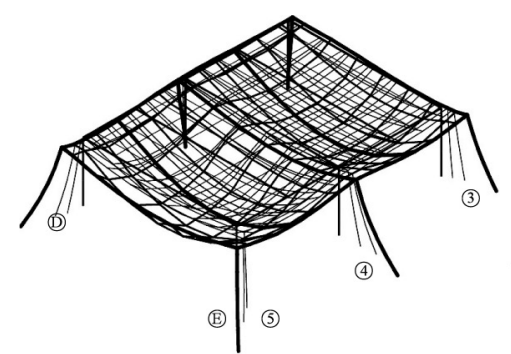

(1) Perspective View

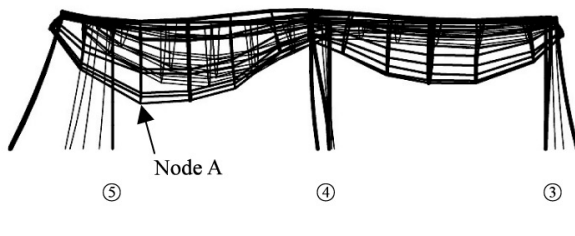

(2) Side View

Figure 20 Thermal Deformation of the Fire Room (30x magnification)

Figure 20 shows the thermal deformation of the local substructure that will be exposed directly to the vehicle fire. The diagram shows the deformation 15, 30, and 45 minutes after ignition. The downward deflection in the floor slabs, small beams, and beams increases with the rising temperature. The deflections of the floor and the small beams are significantly large compared with the deflections of the beams. The 
deflection is largest on the floor slab, as shown in Figure 20(2) (Node A). This implies the contribution of the bending effect due to the temperature gradient, as the difference in the temperature between the heated and the unheated surfaces of the floor slab is extremely large. The corner column is leaning outwards in an oblique direction, due to the two-dimensional elongation of the beams. Therefore, an ordinary column fixed at their bases would have received an even larger two-dimensional bending force.
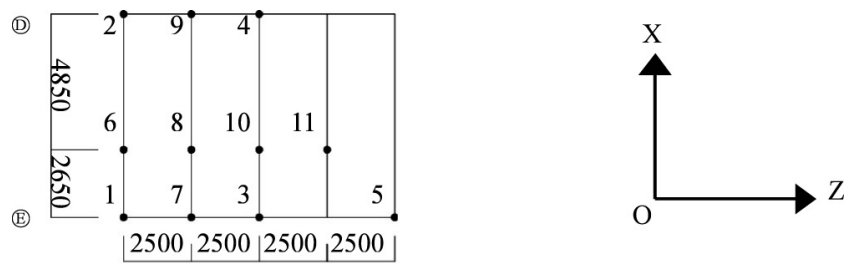

Figure 21 The Locations and the Numbering of the Measured Points (unit: mm)

(Note: The positive direction of the Y-axis is taken to be vertically upwards)

Next, the displacements measured in the experiment are compared with the analytical results. Figure 21 shows the numberings of the measured points and their directions of displacements. For the displacements measured in the experiment, the $1^{\text {st }}$ floor is exposed to the fire. Therefore the fixed points are placed on the $2^{\text {nd }}$ floor side. The results are compared in Figure 22 (a)-(i).

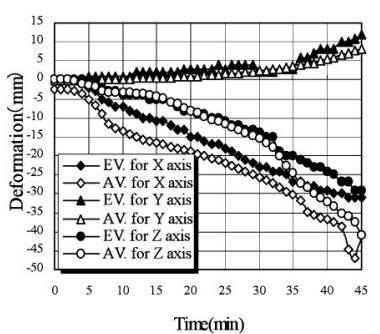

(a) Deformation at Point 1 (Top of the Corner Column)

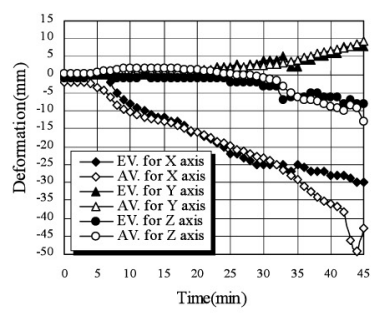

(d) Deformation at Point 3

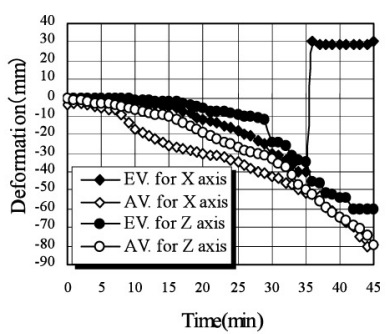

(b) Deformation at Point 1 (Base of the Corner Column)

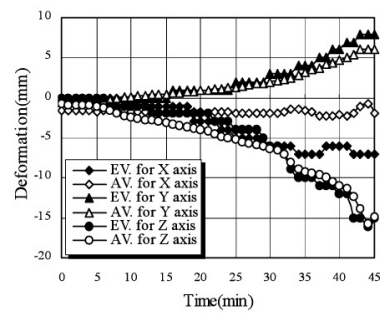

(e) Deformation at Point 4

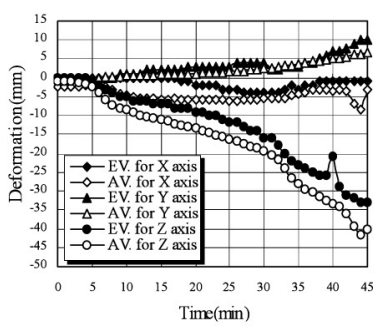

(c) Deformation at Point 2

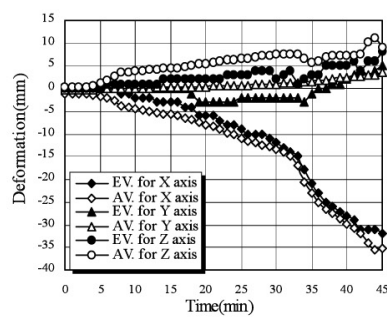

(f) Deformation at Point 5 


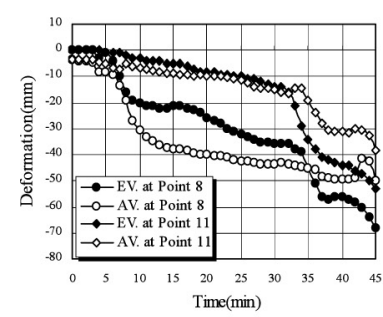

(g) Vertical Deformation at Point 8 and 11(Small Beams)

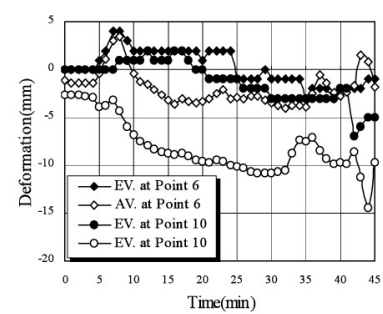

(h) Vertical Deformation at Point 6 and 10 (Beams)

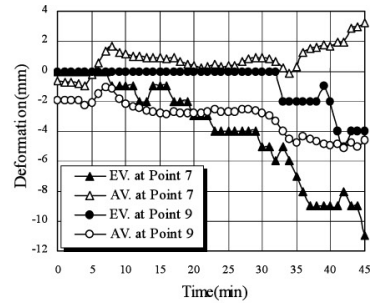

(i) Vertical Deformation at Point 7 and 9 (Beams)

Figure 22 Thermal Deformations at the Measured Points of the Structure (Note: $E V .=$ Experimental Value, $A V .=$ Analytical Value)

The deformations at the top and bottom of the corner column of the $1^{\text {st }}$ floor are shown in Figures 22 (a) and (b). The horizontal deformation in the X and Z directions at the top of the corner column increases significantly following the elapse of time due to the thermal expansion of the beams and the floor slabs. The expansions in the Y (vertical) direction show some increase with the progression of time. However, the value is small compared with the deformation in the horizontal direction. The analytical results and the experimental values coincide well with each other. The horizontal deformations in the $\mathrm{X}$ and $\mathrm{Z}$ directions at the bottom of the corner column, shown in Figure 22 (b), exhibit values that are double the values of the deformations at the top of the corner column shown in Figure 22 (a). The analytical values show slightly larger values compared with the experimental values because the supports at the base of the columns in the current analysis are assumed to be ideal rollers. The experimental and the analytical values in the $\mathrm{X}$ direction do not coincide with each other after the 35 -minute mark. The experimental value increases abruptly (approx. $70 \mathrm{~mm}$ ) in the positive direction at 35-minute mark, and remain constant after that. This is because the displacement-measuring instrument at the bottom of the corner column has gone over the limit and broken off. Next, we will compare the values for the deformation at the top of the external column at measured point 2, as shown in Figure 22 (c). The horizontal deformation in the $\mathrm{Z}$ direction due to the expansion of the beams and the floor slab are showing large values, and the analytical values coincide well with the experiment. This is similar with the deformation at the top of the external columns shown in Figures 22 (d) and $(f)$. Next, we will compare the horizontal deformation at the top of the inner column as shown in Figure 22 (e). In the $\mathrm{Z}$ direction, the analytical and the experimental values coincide well with each other. In the $\mathrm{X}$ direction, the values show slight differences after the 25-minute mark. Next, we will compare the deflections of the small beams shown in Figure $22(\mathrm{~g})$. The analytical and the experimental values for the deflection at the measured point 11 coincide well with each other. On the other hand, the values for the measured point 8 show some differences. In the experiment, the temperatures of the heated surface of the floor slab were measured directly at these points, which are located immediately above the burning cars. When considering the measured point's temperatures to the temperatures of the heated surface, the values will be higher than 
they should be. The temperature distribution of the floor slab are determined based on the temperatures of the heated surface, therefore, as a result, it will be lead to the analytical temperature gradients being larger than those obtained in the experiment. It is the reason that the deflections at Measurement Point 8 for the analytical results have been larger values compared with those recorded in the experiment. The deflections of the beams shown in Figures 22 (h) and (i) are almost negligible compared to the deflections of the small beam. The analytical solutions show similar results.

\subsection{Conclusion of the Comparison with the Large Full-Scale Fire Test}

In the current study, an analytical method of deflection behavior concerning three-dimensional steel frame exposed to fire was proposed, which takes account of the thermal expansion of the floor slab by conceiving the floor slab as a grid of intersecting beams. The method was utilized to analyze the behavior of the deformation of the steel structure in a large full-scale fire test, and the following results were confirmed:

(1) The analytical values for the horizontal displacements of the tops of the columns due to the expansion of the floor and the beams coincide well with those recorded in the experiment.

(2) The floor slabs and the small beams show larger deformation compared with the beams that support the floor slabs owing to the bending effect due to the temperature gradients across the floor slabs.

(3) The analytical values for the deformation of the small beams, that are sensitively affected by the bending effect of the floor slab are greatly dependent on the temperature of the heated surface of the floor slab exposed to fire, therefore, the analytical results only qualitatively coincided with the experimental values.

\section{CONCLUSION}

In the current study, an analytical method of deflection behavior concerning three-dimensional steel frame exposed to fire was proposed, which takes account of the thermal expansion of the floor slab. It was confirmed that the analytical results agree well with those recorded in experiments in which a large full-scale frame was exposed to vehicle fire, and the validity of the proposed method of analysis has been proven.

\section{REFERENCES}

1. Article 107 in The Enforcement Ordinance of The Building Standards Act in Japan, 2002

2. Hikaru Saito: Behavior of an End-Constrained Steel Construction Member Exposed to Fire, Journal of Japan Association for Fire Science and Engineering, Vol.15, No.1, 1966 (in Japanese) 
3. Fukujiro Furumura, Kenji Migita, Takeo Ave, Takeshi Okabe, Wha Jung Kim: Elasto-Plastic Creep Thermal Deformation Behavior of Plastic Designed Steel Frames, Journal of Structural and Construction Engineering, The Architectural Institute of Japan, No.368, pp.68-77, October 1986 (in Japanese)

4. Hideki Uesugi, Hiroshi Koike: Thermal Stress of Steel Structures of Tall Building in Fire (Part 1: Computer analysis method of tall structures exposed to compartment fire), Journal of Structural and Construction Engineering, The Architectural Institute of Japan, No.381, pp.73-80, November 1987 (in Japanese)

5. Takayuki Kitano, Osami Sugawa, Hideaki Masuda, Takeo Ave and Hideki Uesugi: Large Scale Fire Tests of 4-Story Type Car Park (Part1: The behavior of the structural frame exposed to the fire at the deepest part of the first floor), Proceedings of the Fourth Asia-Oceania Symposium on Fire Science and Technology, pp.527-538, 2000

6. H.Saito, H.Uesugi, M.Yamaguchi and A.Kodaira: Thermal Stress and Deformation of Steel Structures of High Rise Buildings in Fire, Fire Safety Science-Proceedings of the Second International Symposium, pp.719-728, 1989

7. Huiqun Lin, Hideki Uesugi: Three Dimensional Analysis Method of High Rise Structure Exposed to Compartment Fire (Part 1: The formulation of restraint force and adjacent displacement for local substructure), Journal of Structural Engineering, The Architectural Institute of Japan, Volume 44B, pp. 1-8, March 1998 (in Japanese)

8. Hikaru Saito: Behavior of End Restrained Concrete Member in Fire, B.R.I Research Paper, No.32, 1968

9. Marc Hoit (Author), Yoshiaki Yamada (Translation and Edition): Computer-assisted Structural Analysis and Modeling, Maruzen, p.220, September 1995

10. Yuguang Li, Takeo Hirashima, Takeo Ave, Hideki Uesugi and Takao Wakamatsu: Three-Dimensional Analysis Method of High Rise Structure Exposed to Compartment Fire (Part 2: Transformations of coordinate about three-dimensional structure), Journal of Structural Engineering, The Architectural Institute of Japan, Volume 52B, pp.65-72, March 2005 (in Japanese)

11. Hidetosi Satoh, Hideki Uesugi, Akio Kodaira and Hikaru Saito: Thermal Stress and Deformation of Steel Structure in Fire (The Influence of Temperature Gradient in Simple Structure, Part 1 and Part 2), The Congress of the Architectural Institute of Japan (Kyushu), pp.1035-1038, October 1989(in Japanese)

12. Masahiro Shoji: Heat Conduction Engineering, University of Tokyo Press, p.61, February 2002 (in Japanese)

13. Becker, J., Bresler, B.: FIRES-RC - A Computer Program for the Fire Response of Structure $\cdots$ Reinforced Concrete Frames, Report No. UCB FRG 74-3, University of California Berkley, July 1974

14. Tasnim Uddin, Charlas G. Culver: Effects of Elevated Temperature on Structural Members, Journal of the Structural Division, ASCE, Vol.101, No.ST7, July 1975 
15. J. Hult (Author), Sumio Murakami (Translation): A Course in the Mechanics of Solids \#4: Creep in Engineering Structures, Baifukan, December 1973

16. Commission of European Communities: Eurocode 4-Design of Composite Steel and Concrete Structures -Part 1-2: General Rules- Structural Fire Design, p.24, pp.52 53, 1994

17. Anderberg, Y. and Thelandersson, S.: Stress and Deformation Characteristics of Concrete at High Temperatures 2. Experimental Investigation and Material Behavior Model, Division of structural Mechanics and Concrete Construction, Lund Institute of Technology, Bulletin No.54, Sweden, 1976 